\title{
Utilization of vegetal fibers for production of reinforced cementitious materials
}

\author{
Viviane da Costa Correia ${ }^{a}$, Sergio Francisco Santos ${ }^{b}$, Holmer Savastano Jr. ${ }^{a}$, Vanderley Moacyr John ${ }^{c}$ \\ a University of São Paulo (USP), Department of Biosystems Engineering, Research Nucleus on Materials for Biosystems, SP, Brazil \\ ${ }^{\text {b }}$ São Paulo State University (UNESP), Department of Materials and Technology, Campus Guaratinguetá, SP, Brazil \\ ' University of São Paulo (USP), Department of Civil Construction Engineering, SP, Brazil
}

Received: 19 December 2017 / Accepted: 19 March 2018 / Published online: 04 April 2018

(C) The Author(s) 2017. This article is published with open access and licensed under a Creative Commons Attribution 4.0 International License.

\begin{abstract}
Vegetal fibers produced from agroindustrial resources have been used as reinforcement in cementitious materials in the macro, micro and nanometric scales. The cellulosic pulp, besides being used as the reinforcing element, is also the processing fiber that is responsible for the filtration system in the Hatschek method. On the other hand, the nanofibrillated cellulose has the advantage of having good mechanical performance and high specific surface, which contributes to improve the adhesion between fiber and matrix. In hybrid reinforcement, with both micro and nanofibers, the cellulose performs bonding elements with the matrix and acts as stress transfer bridges in the micro and nano-cracking network, with corresponding strengthening and toughening of the cementitious composite. Some strategies are studied to mitigate the degradation of the vegetal fibers used in cost-effective and nonconventional fiber cement, as well as to reach sustainable fiber cement production. As a practical example, accelerated carbonation curing at early age is a developing technology to increase the durability of composite materials: it decreases porosity, promotes a higher density in the interface, generating a good fiber-matrix adhesion and a better mechanical behavior. Thus, vegetal fibers are potentially applicable to produce high mechanical performance and sustainable cementitious materials for use in civil construction.
\end{abstract}

Keywords: Sustainable fiber cement; Carbonation; Macrofibers; Pulp; Nanofibrillated cellulose

\section{Introduction}

The construction industry is a major driver of the global economy both in industrialized and in developing regions. As a consequence, this sector is associated with several environmental problems [1,2].

The construction industry, in general, and the Portland cement value chain in particular, are material intensive. From environmental point of view, civil construction consumes more than $50 \%$ of the world's raw materials [3]. Cement-based materials waste is an obvious and almost unexplored option. Combined with natural aggregates, it consumes a growing share materials used by modern society, a fraction that surpasses $1 / 3$ of the total materials [4]. The Portland cement industry also releases about 6-8\% of the anthropogenic $\mathrm{CO}_{2}[1,5]$. In order to comply with the Paris agreement on climate change [6], the cement value chain has to innovate, going beyond the usual clinker substitution, by blast furnace slag or traditional pozzolans, and energy efficiency. This will probably imply in adapt to local constraints, such as availability of raw, preferable waste, materials and different demands from each market.
Silica-fume, metakaolin and fly ash are the most used pozzolanic additions in combination with ordinary Portland cement and carbonate filler [7]. The particle size distribution of these materials is a very important parameter for processing many cement products, as powder packing can be tailored by selecting of raw materials with suitable sizes and fractions. In the design of the bulk cementitious matrix of fiber-cement, various raw materials must be properly combined and adjusted, with different particle size range. Besides, some basic characteristics of the interfacial transition zone (ITZ) between particles in Portland cement paste with mineral additions and between cement paste and short lignocellulose fibers must be studied, evaluated and correlated to mechanical properties of these composites. The pozzolanic additions can react with the free portlandite available in the ITZ to form extra calcium silicate hydrates (CSH) and help with denser and less aggressive interface with the vegetal fibers [8]

Pozzolans can be produced by the use of biomass for energy co-generation, especially if firing conditions are controlled. For example, sugar cane bagasse ash and rice husk ash are reported elsewhere to perform pozzolanic activity. 
Approximately 140 billion metric tons of biomass are produced every year in the world from agriculture. For each ton of processed sugarcane, there are $270 \mathrm{~kg}$ of bagasse [5,9-12]. In India, for instance, it is reported that about 600 $\mathrm{Mt} /$ year of rice husk have been generated from agricultural sources alone. If fired during industrial processing, for average losses on ignition of 7\%, $42 \mathrm{Mt} /$ year of ashes could be produced in one year; approximately $15 \%$ of India's cement production [10].

Another option for mitigation strategy is dematerialization. The use of small volume fraction of fibers is known to allow the production of thin sheets that can be used in roofing, partition walls and even as slabs, increasing the efficiency of the resources used and therefore, reducing materials intensity of this industry. In developing countries, like Brazil, Hatschek produced lightweight fiber cement components are one of the most popular solutions for roofing, a market conquered by the corrugated sheets of asbestos-reinforced or synthetic fiber-reinforced products (Fig. 1).

Hatschek was the first method of fiber cement manufacturing, and it was invented by Ludwig Hatschek in the 1890s. This process begins from slurry mixture with cellulose pulp, reinforcing fibers, Portland cement and mineral additions in water. This fed into a papermaking like machine in which a cylindrical sieve or sieves rotate through the slurry. The solids are deposited on the sieve, which on each rotation transfers the layer of solids onto a continuous belt. The layers are built up to the desired thickness and then removed and, if necessary, compressed by stack pressing [13].

Nowadays, almost all asbestos fiber is replaced by plastic counterparts such as polypropylene (PP) and polyvinylalcohol (PVA), which are alkali resistant [14]. However, the synthetic fibers are non-renewable, expensive and their production consumes a significant amount of energy and petrochemical raw materials [15]. The asbestos free solution is more expensive than the asbestos reinforced composites, especially due to the increase of the cost of raw materials.

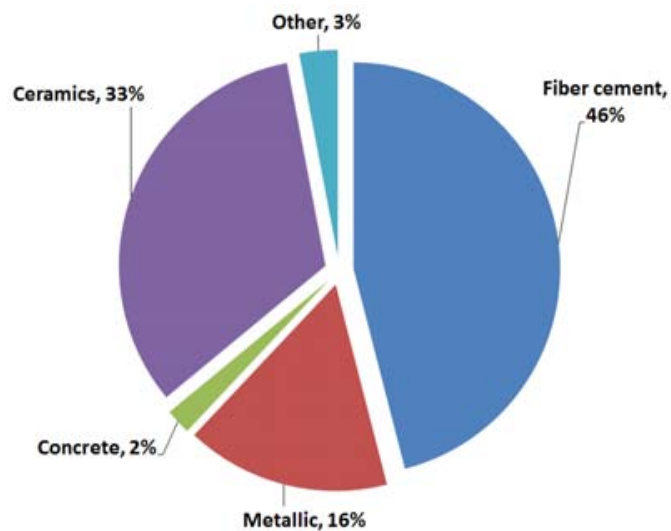

Figure 1. Various types of materials used for popular solutions of roofing in Brazil (Based on [16]).

In many countries, the transition from asbestos reinforced to asbestos free fiber cement (due to health concerns) implied in a reduction of market share of this lightweight fiber cement-based roofing, which had been replaced by roofing technologies frequently heavier and costly, a factor that has social and environmental implications. The use of vegetal fibers to produce low-cost, sustainable fiber cement composites have been discussed since 1988 [17-20] and can be a local option in many regions of the world.

In this paper, we will discuss the potential of bio-based fibers to promote a resource-efficient and low-carbon cement based value chain.

\section{The potential of bio-based fibers}

In recent years, an increasing attention has been given to the use of cellulose fibers as alternatives to replace plastic fibers in air-cured composites $[7,15,16,19]$. However, air cured fiber cement reinforced exclusively with cellulose fibers presents some reduction in the mechanical performance. It is due to low durability of the vegetal fibers in a highly alkaline environment, such as the cementitious matrix. Currently, plastic fibers are the main reinforcement of fiber cement composites, because these fibers are less sensitive to alkali attack and possess good mechanical properties, resulting in composites with better performance in the longterm. Cellulose fibers are used only as process fibers in the Hatschek production of air cured plastic fiber reinforced components [7].

The commercial use of vegetal fiber is still limited. These natural fibers are a functionally graded material that has a hierarchical structure in the macro, micro and nanometric scales with interest as reinforcement in cementitious materials [21,22]. Motivations for their use include the decreased raw materials costs and a potential contribution to reducing environmental impacts of fiber cement sheets, because they are renewable, may require lower amounts of energy to produce and, being cheap, may help lightweight fiber cement to remain in the market. Additionally, vegetal fibers can be locally produced, generating local social and economic benefits. Vegetal fiber from different origins has been studied as a reinforcement of cement-based matrices, such as banana [23], sisal [24-26], hemp [27], green coconut $[28,29]$, sugarcane bagasse [30], curauá [31,32], bamboo pulp [22,33,34], pine and eucalyptus pulps [15,35-37].

Nevertheless, the reduction of vegetal fiber durability is caused mainly by the alkaline $(\mathrm{pH} \sim 12-13)$ environment of the cement matrix and gradually filling of the inner cores of the vegetal fibers with the cement hydration products, leading to the embrittlement of the fibers, and reducing their mechanical performance [38-40]. Some strategies to mitigate the degradation of the vegetal fibers used as reinforcement in cost-effective and non-conventional fiber cement, as well as to reach a more sustainable fiber cement production are indicated in Fig. 2, such as functionally graded materials [41,42], reduction of the consumption of Portland cement [1], utilization of different binders $[5,37,43,44]$, mineral additions from agroindustrial wastes [9-12] carbonation curing $[45,46]$ and nanofibrillation of the lignocellulosic fiber [21]. 


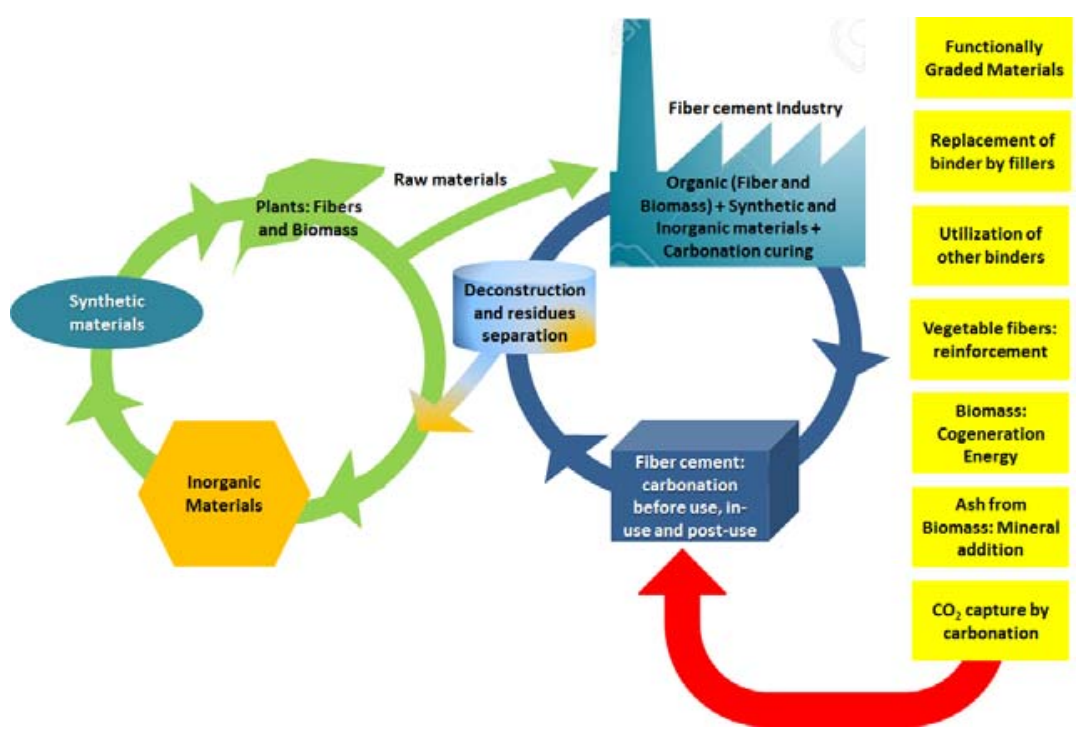

Figure 2. Schematic diagram showing a concept process consisting of different approaches to improve the sustainability of the fiber cement industry.

In order to offer durability and resilience of the fiber cement reinforced with vegetal fiber, contribute to infrastructure sustainability, extended service life and expand the range of functional uses of vegetal fibers in construction applications, it is necessary to adopt systemic research using the concept of integrated structures and materials design as represented in Fig. $3[32,47]$. Thus, material properties serve as a natural interface between structural engineering and materials engineering.



Figure 3. Schematic diagram of Integrated Structures and Materials Design (Based on [47]).

Thus, to design cementitious composites reinforced with vegetal fibers to meet the concept of integrated structures and materials can be considered a complex and systematic task. For example, the project design must consider the interrelationship between interfacial transition zone, fibers, matrix and processing method as depicted in the schematic illustration showed in Fig. 4.

These approaches may result in efficient gains, cost reduction and contribution to sustainable development with regard to environmental aspects. Therefore, vegetal fibers have attracted great interest because of their regional availability and high specific tensile strength (associated to their low density). However, their effective consolidation as raw material in the civil construction industry involves a great technical and scientific effort.

\section{Study on the potential of two lignocellulosic material}

\subsection{Cellulosic pulp}

In addition to the macrofibers, the microfibers obtained through chemical and mechanical pulping are also used as reinforcement of cementitious materials. In such composites, the cellulosic pulps are used to promote packaging with the particles of the matrix. In the industrial production of fiber cement (Hatschek process), the cellulosic pulp is used to form a network for retention of the cement particles during the water drainage stage $[7,15]$.

The advantage of the use of pulp as reinforcement in comparison to macrofibers is the greater surface roughness of the fiber, which increases the adhesion capacity between the fiber and the matrix. Another advantage is that the short length of these fibers facilitates their distribution and homogenization in the matrix, improving the fiber-matrix bond and, consequently, the reinforcing efficiency [48-50]. In addition, the pulp can originate from wood (pine and eucalyptus, e.g.) and other non-wood lignocellulosic fibers.

Wood pulps (pine and eucalyptus) were used in the range of $4-10 \%$ by mass, as reinforcement of cementitious matrices [35-37,46,51,52]. Non-wood fibers are also commonly used as reinforcement of cementitious composites, such as sisal [39,53-56], banana [23,53-55], bamboo [22,33,34], fique [35], cotton [57] and agricultural waste fibers [30]. 


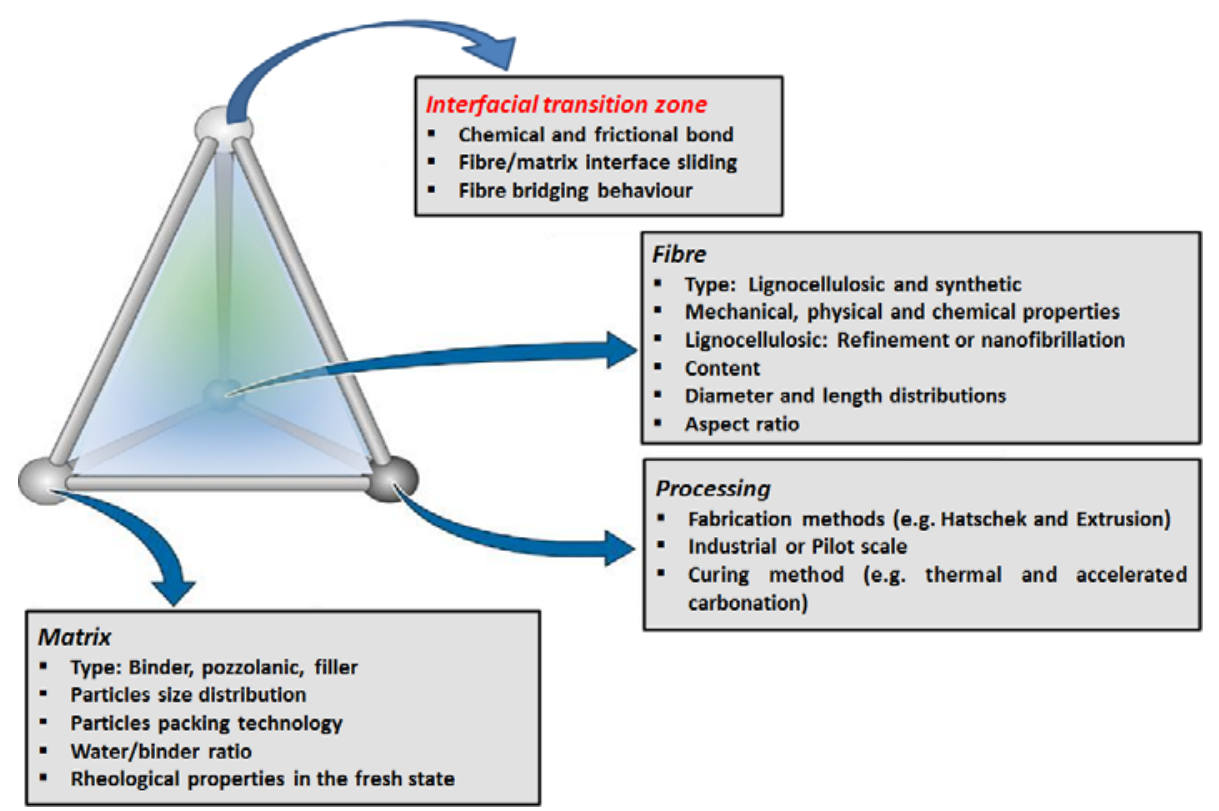

Figure 4. The tetrahedral interrelation of the main constituents of the cement based composite design. Adapted from [8].

Khorami and Ganjian [30] compared the flexural performance of cementitious composites reinforced with contents of $2 \%$ and $4 \%$ by mass of the sugarcane bagasse, wheat wastes and eucalyptus pulp. In that study, the content of $2 \%$ of fibers promotes no significant changes in flexural performance of the composites in comparison to composites without fibers; however, the content of $4 \%$ of pulp improved significantly the flexural strength of the composites. Khorami and Ganjian [58] evaluated the effect of different residual Kraft pulp contents (1-14\%) on the flexural strength of cementitious composites. The authors concluded that the optimum reinforcement content was $8 \%$ by mass, where the modulus of rupture value was $250 \%$ higher than composites with $1 \%$ fiber.

Correia et al. [22] used bamboo pulp, produced by the organosolv pulping process, in different contents $(6 \%, 8 \%$, $10 \%$ and $12 \%$ by mass) as reinforcement of cementitious composites, with matrix composed by Ordinary Portland cement type CP V-ARI ( $75 \%$ by mass) correspondent to ASTM-C150 Type I, and metakaolin ( $25 \%$ by mass), and the mechanical results from bending test are presented in Fig. 5 . The fiber cement is a component of the civil construction, which is submitted usually to the flexural effort. The content of $8 \%$ of bamboo pulp was sufficient to ensure the capacity of reinforcement before and after the crack propagation. The mechanical strength of the composites reinforced with $10 \%$ and $12 \%$ of pulp was lower due to the greater porosity caused by the higher pulp content. However, the toughness in the post-fissured condition was significantly higher for the higher amounts of pulp.

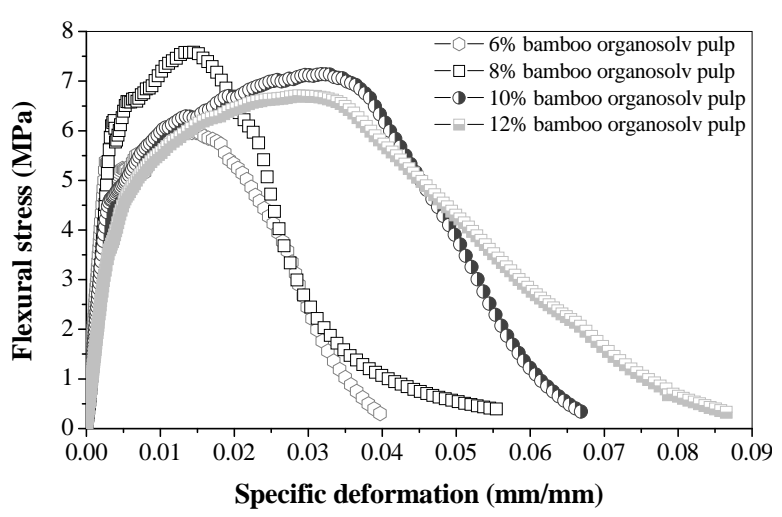

Figure 5. Typical stress - strain curves of the composites containing $6,8,10$ and $12 \%$ bamboo organosolv pulp during flexural tests after 8 days of thermal curing. Adapted from [22].

\subsection{Nanofibers as reinforcement of cement- based composites}

Nanofibrillated cellulose consists of a bundle of stretched cellulose chain molecules with long, flexible and entangled cellulose nanofibers with dimensions of approximately 1-100 $\mathrm{nm}$ and they are composed of alternating crystalline and amorphous regions [59-61]. They are produced from the isolation of cell wall of the lignocellulosic materials using shear forces without chemicals. Fig. $6 \mathrm{a}$ and Fig. 6b, provided by Correia et al. [21], presents a visual result of the transformation of the cellulose pulp prior to nanofibrillated cellulose after 5 cycles of nanofibrillation by the grinding process. 


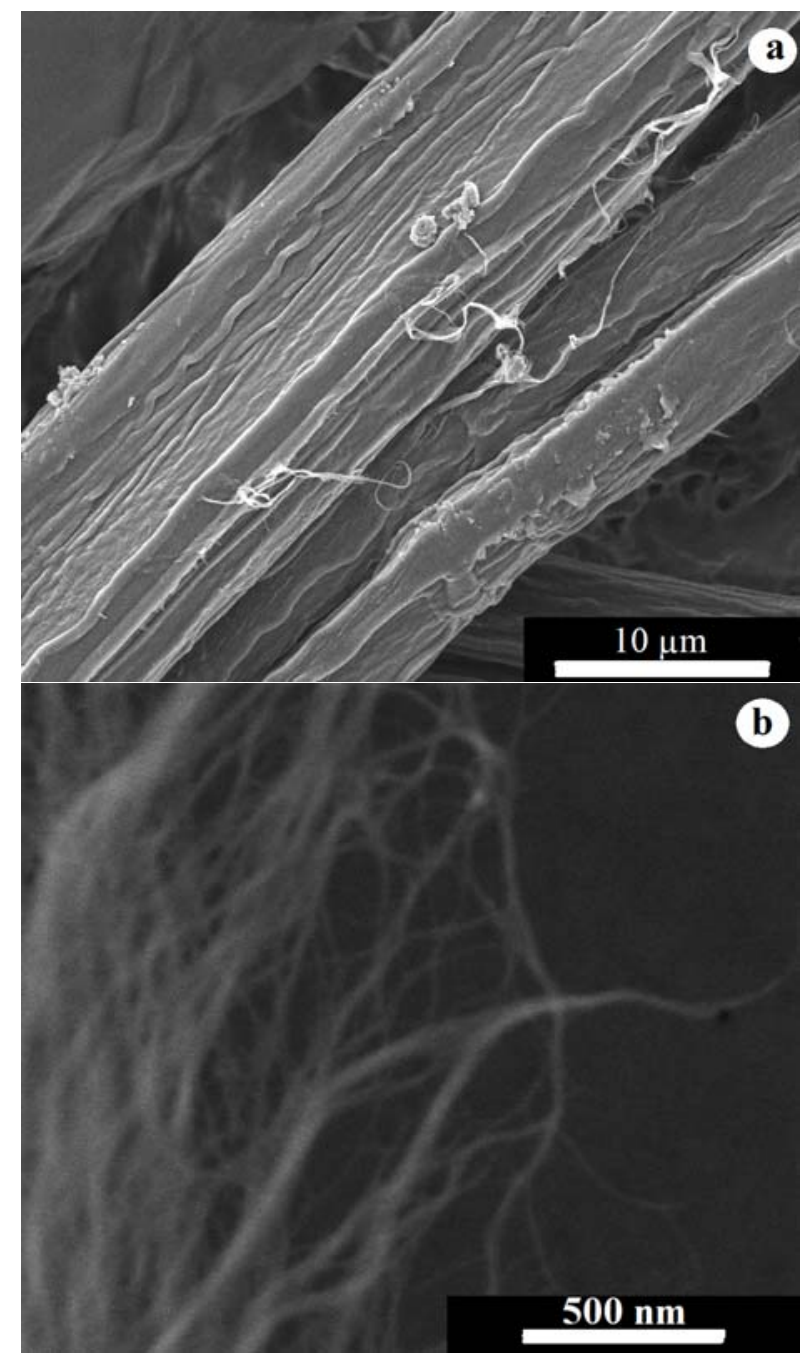

Figure 6. Unbleached bamboo pulp (a) and nanofibrillated cellulose from bamboo pulp after 5 nanofibrillation cycles. Adapted from [21].

Vegetal fibers in nanoscale have also been used as reinforcement of cementitious composites with the objective of reinforcing materials. Nanofibrillated cellulose has the advantage of high modulus of elasticity ( $82.3 \mathrm{GPa})$ [10] and high specific surface area $\left(50-70 \mathrm{~m}^{2} / \mathrm{g}\right)$ [62], in comparison to cellulosic pulp, which contributes to improve the adhesion between fiber and matrix. In addition, the nanofibers act as stress transfer bridges in the nano-cracks during loading [63-65]. According to Han et al. [66], the nanofibers can delay the beginning of the crack progression at the nanoscale and therefore, higher loads are required to start cracking the composite, which indicates the increase of the mechanical strength of the cementitious matrix.

Most of the work already published focuses on the use of carbon nanofibers and nanotubes as reinforcement due to the mechanical properties of these nanofibers, such as high modulus of elasticity (1TPa for nanotubes), high tensile strength (50-200 GPa) and $280 \%$ increase in the rupture strength $[64,67]$. When using conventional mixing methods, there is a strong tendency of agglomeration of the nanofibers, which increases the water demand for adequate rheological behavior, which increases the variability of the composites properties. However, if the production process succeeds to adequately disperse fibers and keep the water demand in control, besides the mechanical performance improvement, they can reduce the electrical resistivity and contribute to the increase of the durability of cementitious composites due to the reduction of water permeability [6870]. However, the use of carbon nanofibers and nanotubes increases the cost of the final composite.

Thus, the nanofibers from vegetal resource are an alternative as reinforcement of cementitious materials at the nanoscale, since these nanofibers have as advantages, abundance worldwide, it is a renewable source, they have low density and high mechanical resistance. The cellulosic nanofibers, in general, have low modulus of elasticity in comparison to the fibers of carbon, glass and steel, and consequently, the cellulosic nanofibers promote a greater toughening of the brittle matrices [21,71,72].

The literature presents works on cementitious composites reinforced with vegetal nanofibers obtained by different methods, such as, acid hydrolysis and mechanical nanofibrillation. Cellulose nanocrystals are produced by acid hydrolysis, and are added to a cement matrix to improve the physical and mechanical properties. The work developed by Cao et al. [73-75] was the first one published in high impact journals on the use of cellulose nanocrystals in cementitious materials [76].

The results presented by Cao et al. $[73,75]$ show that in some cements cellulose nanocrystals contributed to the improvement in the cement hydration and of microstructure of matrix, and consequently, the addition of cellulose nanocrystals increased the flexural strength of composites. The water diffusion rate in the high-density hydrated calcium silicate increased with the addition of cellulose nanocrystals and the flexural strength of the composites increased 20$30 \%$ with the addition of $0.2 \%$ by volume of nanocrystals [73-75].

Thomson et al. [77] produced hybrid composites by slurry vacuum dewatering followed by pressing process - a system that overcomes the difficulties associated to the demand of high amounts of mixing water for dispersing nanofibers and other nanoparticles - reinforced with $8 \%$ of cellulosic pulp and the contents of $0.5,1.0$ and $2.0 \%$ of cellulose nanocrystals. The mechanical results showed increased modulus of rupture with up to $0.5 \%$ of nanocrystals.

The cellulose nanofibers obtained by the mechanical process (nanofibrillation) appear to have advantages over cellulose nanocrystals.

Nanofibrillated cellulose has higher specific surface area and higher aspect ratio than cellulose nanocrystals, which increases the interaction between fibers and matrix, promoting the higher mechanical resistance of the composites reinforced with nanofibrillated cellulose $[21,72,78]$.

One pioneering work about the use of nanofibrillated cellulose as a reinforcement of cementitious materials was carried out by Ardanuy et al. [78,79]. In these studies, the authors used $3.3 \%$ (by mass) of nanofibrillated cellulose from sisal as reinforcement of mortar in comparison to 
mortar reinforced with the same content of cellulosic pulp. The mortar reinforced with nanofibers had an increase of $26.4 \%$ in the tensile strength under flexural load and a corresponding increase of $41.5 \%$ in the modulus of elasticity, compared to mortar reinforced uniquely with pulp.

Onuaguluchi et al. [80] produced cement pastes by incorporating of lower contents of nanofibrillated cellulose originated from bleached pine pulp. The authors used the contents of $0.05 \%, 0.1 \%, 0.2 \%$ and $0.4 \%$ of nanofibrillated cellulose. The results showed that the reinforced pastes with $0.1 \%$ of nanofibers had an increase of $106 \%$ in flexural strength and of $184 \%$ in energy toughness, compared with pastes without nanofibers with the same water/cement ratio of 0.5 . According to the authors, the improvement of these properties is attributed to the characteristics of high specific surface area of nanofibers, which increases the interface between fiber and matrix, and the high hydrophilicity of the cellulose, which promotes better adhesion with the cement. However, the pastes with contents above $0.1 \%$ did not have a good mechanical behavior due to the agglomeration of the nanofibers.

The efficiency of the nanofibers as reinforcement in the cement-based composites has been studied by the Research Nucleus on Materials for Biosystems, at University of São Paulo, Brazil. Cement composites reinforced with nanofibrillated cellulose were produced from bamboo organosolv pulp, and were compared to the composites with $8 \%$ of bamboo organosolv pulp and the hybrid composites with $8 \%$ total cellulose but different proportions between pulp ( $7 \%, 6 \%$ and $5 \%)$ and nanofibrillated $(1 \%, 2 \%$ and $3 \%)$. All samples were produced by vacuum dewatering process followed by compression and the matrices were composed by Ordinary Portland cement type CP V-ARI ( $75 \%$ by mass) correspondent to ASTM-C150 Type I, and by the ground limestone filler ( $25 \%$ by mass) $[13,53]$.

The stress-strain curves presented in Fig. 7 demonstrate that composites with nanofibrillated cellulose have higher flexural strength than those reinforced by conventional cellulose pulp. However, the composites reinforced with only nanofibrillated cellulose showed a fragile behavior, with much lower toughness energy than those hybrid composites reinforced, which combined cellulose pulp and nanofibrillated cellulose. Hybrid composites presented much better performance than the reference composites reinforced with pulp only. In hybrid reinforcement, with micro and nanofibers, nanofibrillated cellulose seems to bond strongly with the matrix and acts as stress transfer bridges in the micro and nano-cracking, a mechanism that can explain the measured strengthening of the composite. However, the conventional pulps increase the tenacity due to a well-known pullout process, despite reducing the flexural strength, probably because they act as large defects in the matrix.

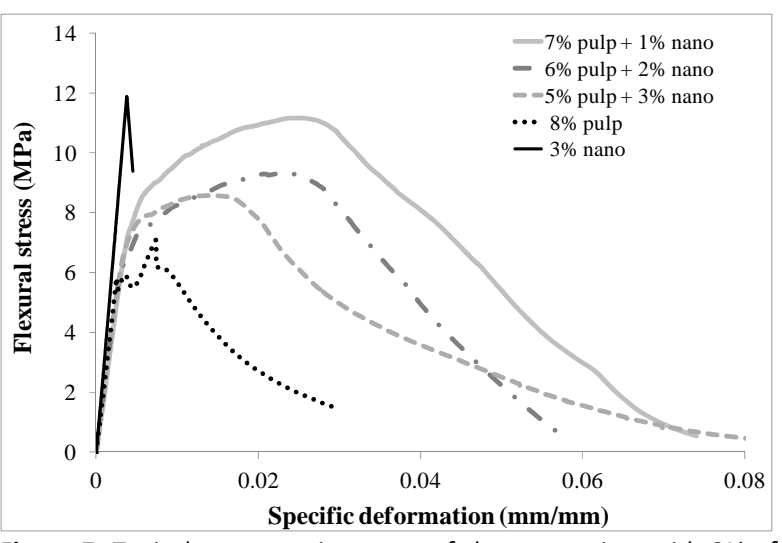

Figure 7. Typical stress-strain curves of the composites with $3 \%$ of nanofibrillated cellulose, the hybrid composites with different content of pulp and nanofibrillated cellulose and composites with $8 \%$ of pulp at 8 days.

The values of the modulus of rupture of the hybrid composites and of the composite reinforced with just 3\% of nanofibrillated cellulose are significantly higher in comparison to the composite without nanofibers $(8 \%$ of pulp). The modulus of rupture is directly associated with the existence of the defects in the matrix and at the interfacial transition zone (ITZ) between the fiber and the matrix, and with the performance of the fibers used as reinforcement. The ITZ can be defined as the three-dimensional boundary between the fiber and the matrix. In this region, the interactions can occur through various mechanisms. The mechanisms are described as: (i) micromechanical interlocking, (ii) permanent or induced dipole interactions, (iii) chemical bonding, (iv) chain entanglement/fibrillation, and ( $v$ ) adhesion by embrittlement/mineralization of the fiber [8]. The nanofibrillated cellulose promoted the improvement of the stress transfer throughout the bulk of the composites when they were subjected to loading. Nanofibrillated cellulose also contributed to the increase of the physical and chemical adhesion, friction and mechanical anchorage with the matrix, induced by its high specific surface area. Besides, it has a better mechanical anchorage in the cementitious matrix without the effect of the drying shrinkage of fibers [8].

The existence of branches of the fibrillated nanocellulose increases the anchoring capacity of the nanofibrillated cellulose with pulp and matrix. The ability to form stress transfer bridges between the nanofibrillated cellulose and the matrix can be illustrated in Fig. 8 .

Therefore, these results show that the use of nanofibrillated cellulose is effective for increasing the mechanical performance of cementitious materials. However, there is no consensus regarding the optimum nano-reinforcement content used to improve the properties of the cement-based materials. 


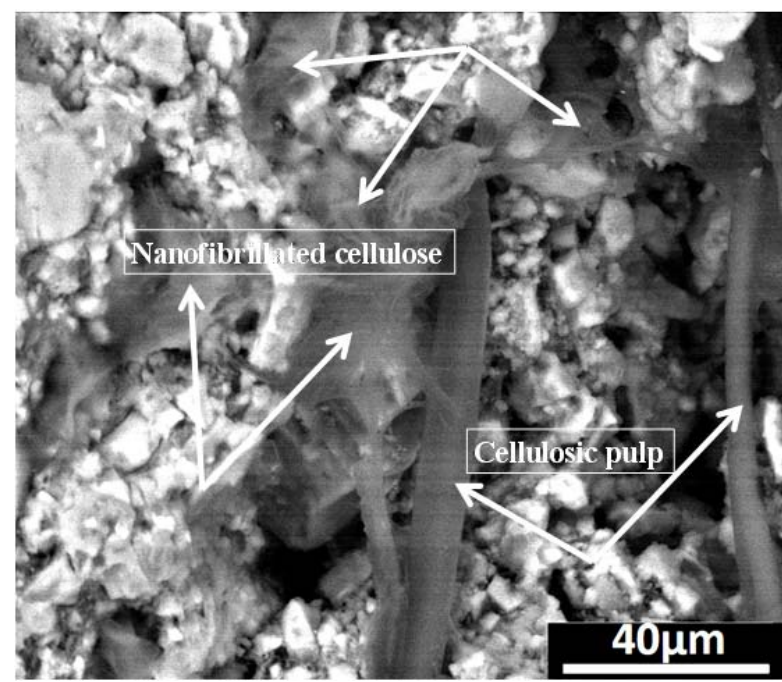

Figure 8. Micrograph of hybrid composite showing the adhesion capacity of nanofibrillated cellulose with the pulp and cement matrix.

\section{Accelerated carbonation curing for cement- based composites}

Despite the high performance of cellulose as reinforcement of cement matrices, it has been reported in the literature that vegetal fibers have low durability in an alkaline matrix, such as cement [19]. A way to overcome the alkaline degradation of the fibers is neutralization by accelerated carbonation curing, which also reduces total porosity improving mechanical resistance of the matrix $[21,36]$ and densifies the fiber/matrix interface, which may reduce the fracture energy of the composite. Carbonation is also a carbon capture and storage process of cement based materials for which kinetics is accelerated in porous thinsections such those of fiber cement composites, and therefore helps $\mathrm{CO}_{2}$ mitigation.

Santos et al. [81] evaluated the effect of accelerated carbonation in supercritical condition on extruded fiber cement reinforced with bleached eucalyptus pulp and residual sisal fibers after 3 days of initial curing and after 200 cycles of accelerated aging (soak and dry cycles). According to results presented in Fig. 9, after accelerated aging the average values of the energy of fracture of the carbonated and non-carbonated composites reduced $28 \%$ and $56 \%$ respectively. This result shows evidence of the improved conservation of microstructural stability and of the toughness of cementitious composites reinforced with vegetal fibers after curing by accelerated carbonation in supercritical conditions.

The results achieved by Urrea-Ceferino et al. [36] show that accelerated carbonation curing reduces matrix alkalinity and mitigates the cellulose degradation in cementitious composites.

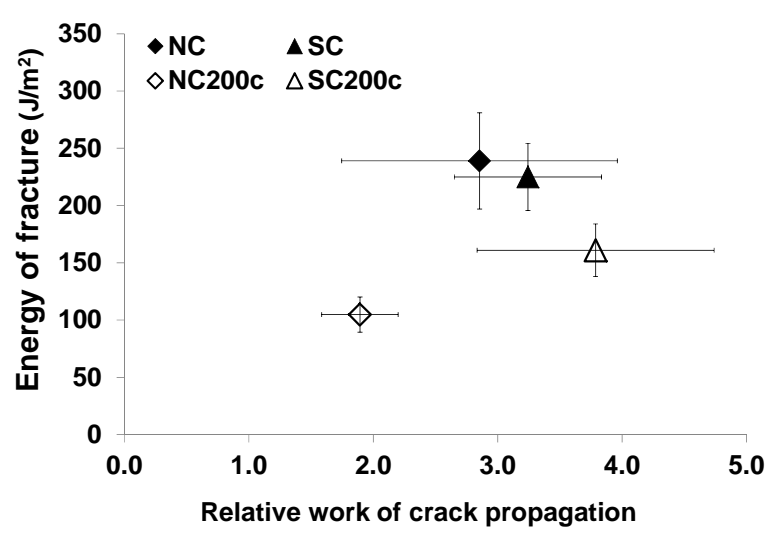

Figure 9. Energy of fracture versus relative work of crack propagation of extruded cellulosic fiber cement non-carbonated (NC) and submitted to supercritical $\mathrm{CO}_{2}(\mathrm{SC})$, before and after exposure to 200 soaking and drying cycles (200c) (Based on [81]).

Table 1 presents the results of the study developed by Correia et al. [82]. The authors studied the effect of hybrid reinforcement (bamboo nanofibrillated cellulose + bamboo pulp) in the performance of carbonated cement composites produced by the extrusion process in comparison to carbonated composites reinforced with only bamboo pulp, at 28 days and after 200 cycles of immersion and drying. The results indicate that the nanofibers present a higher contribution to delay the onset of crack propagation and its potential to act as stress transfer bridges in the nanocracking, mainly after 200 cycles of immersion and drying. The results of flexural stress (MOR) and energy of fracture shows that after accelerated aging the nanofibrillated cellulose preserved partially its ability to form bonds, once the fibers have remained undamaged [82].

Table 1. Mechanical performance of hybrid composites and composites reinforced with pulp at 28 days and after 200 cycles of immersion and drying [83].

\begin{tabular}{|c|c|c|c|}
\hline Composites & & $\begin{array}{l}\text { MOR } \\
(\mathrm{MPa})^{*}\end{array}$ & $\begin{array}{l}\text { Energy of } \\
\text { Fracture }\left(\mathrm{J} / \mathrm{m}^{2}\right)^{*}\end{array}$ \\
\hline \multirow[t]{2}{*}{28 days } & $8 \%$ pulp $+1 \%$ NC & $19.9 a$ & $421.8 \mathrm{a}$ \\
\hline & $9 \%$ pulp & $14.8 \mathrm{~b}$ & $394.7 a$ \\
\hline Aged & $8 \%$ pulp $+1 \%$ NC & $20.1 a$ & $382.2 a$ \\
\hline (200 cycles) & $9 \%$ pulp & $17.8 \mathrm{~b}$ & $379.1 a$ \\
\hline
\end{tabular}

*Average values followed by the same letters do not differ significantly by the Tukey test $(p<0.05)$.

Thus, the potential of the use of nanofibrillated cellulose as a reinforcing element of cementitious materials to increase the mechanical performance of these materials was assessed. Additionally, the use of accelerated carbonation curing optimize the effect of nanofibrillated cellulose, reducing pore size and porosity, densifying the nanofiber / matrix interface and increasing the durability of the nanofibers in the alkaline environment.

\section{$5 \quad$ Final remarks}

Biomass has been a source of materials for long time. For the cement-based industry, biomass can produce, among other raw materials, pozzolanic ashes and fibers. The abundance of the vegetal fibers in all regions of the world, their physical 
and mechanical properties, make of these materials an interesting option for reinforcement for inorganic matrices.

The nanofibrillated fibers have further advantages over cellulose pulp microfibers, and other vegetal fibers for the use as reinforcement, including their higher specific surface area, which favors the adhesion with the matrix. They have also lower lignin content, which reduces alkaline susceptibility. Cellulose nanocrystals have also a potential in cement, including because they may interfere with cement hydration kinetics. As with all nanoparticles, dispersion and water demand for good rheological behavior are a major challenge. Vacuum dewatering production process, which is used worldwide by the fiber cement industry for more than one century - seems to be the easier way to avoid this complication, but other routes can also be feasible with adequate technology.

Durability of these fibers in alkaline Portland cements is a challenge. Accelerated carbonation cure reduces alkalinity of the matrix and mitigates the cellulose degradation in cementitious composites, meanwhile captures $\mathrm{CO}_{2}$. Additionally, accelerated carbonation curing favors porosity refining and increases densification of the fiber/matrix interface, thus improving the mechanical performance of cementitious composites reinforced with vegetal fibers.

Finally, it is possible to state that cement based composites reinforced with vegetal fibers are technically possible to be produced and used in civil construction in regions where they are abundant, but their effective consolidation as raw material still involves a great technical and scientific challenge.

\section{Acknowledgments}

The authors would like to thanks the financial support offered by Research Foundation of the Sao Paulo State FAPESP (Grants $n^{\circ}$ : 2015/21079-0, 2012/51467-3) and National Council for Scientific and Technological Development, CNPq (Grants no 406429/2015 and 312151/2016-0) and Research Nucleus on Material for Biosystems (NAP-BIOSMAT, Grant $n^{\circ}$. USP 12.1.17620.1.9), Brazil.

\section{References}

[1] SA. Miller, VM. John, SA. Pacca, A. Horvath, Carbon dioxide reduction potential in the global cement industry by 2050. Cem Concr Res (2018) In Press. https://doi.org/10.1016/i.cemconres.2017.08.026

[2] S. Amziane, M. Sonebi, Overview on bio-based building material made with plant aggregate. RILEM Tech Lett (2016) 1: 31-38. https://doi.org/10.21809/rilemtechlett.2016.9

[3] European Commission, Final Communication from the Commission: Roadmap to a Resource Efficient Europe, Brussels, 2011, 26p.

[4] F. Krausmann, S. Gingrich, N. Eisenmenger, K-H. Erb, H. Haberl, M. Fischer-Kowalski, Growth in global materials use, GDP and population during the 20th century. Ecol Econ (2009) 68: 26962705. https://doi.org/10.1016/j.ecolecon.2009.05.007

[5] J. Payá, J. Monzó, MV. Borrachero, L. Soriano, JL. Akasaki, MM. Tashima, New inorganic binders containing ashes from agricultural wastes. In: H. Savastano Jr, J. Fiorelli, SF. Dos Santos (Eds.). Sustainable and Nonconventional Construction Materials using Inorganic Bonded Fiber Composites. Woodhead Publishing, Duxford,
2017, 127-164.

https://doi.org/10.1016/B978-0-08-102001-2.00006-1

[6] United Nations Framework Convention on Climate Change, 2015

[7] EM. Bezerra, AP. Joaquim, H. Savastano Jr., VM. John, V. Agopyan, The effect of different mineral additions and synthetic fiber contents on properties of cement based composites. Cem Concr Compos (2006) 28(6): 555- 563. https://doi.org/10.1016/j.cemconcomp.2006.02.001

[8] SF. Santos, RS. Teixeira, H. Savastano Jr., Interfacial transition zone between lignocellulosic fiber and matrix in cement-based composites. In: H. Savastano Jr., J. Fiorelli, SF Dos Santos (Eds.). Sustainable and Nonconventional Construction Materials using Inorganic Bonded Fiber Composites, Woodhead Publishing, Duxford, 2017, 27-68. https://doi.org/10.1016/B978-0-08-102001-2.00003-6

[9] GC. Cordeiro, RD. Toledo Filho, LM. Tavares, EMR. Fairbairn, Experimental characterization of binary and ternary blendedcement concretes containing ultrafine residual rice husk and sugar cane bagasse ashes. Constr Build Mater (2012) 29: 641-646. https://doi.org/10.1016/j.conbuildmat.2011.08.095

[10] F. Martirena, J. Monzó, Vegetable ashes as Supplementary Cementitious Materials. Cem Concr Res (2018) In Press. https://doi.org/10.1016/i.cemconres.2017.08.015

[11] GA. Dantas, LFL. Legey, A. Mazzone, Energy from sugar cane bagasse in Brazil: An assessment of the productivity and cost of different technological routes. Renew Sust Energ Rev (2013) 21: 356-364. https://doi.org/10.1016/j.rser.2012.11.080

[12] CL. Pereira, H. Savastano Jr., J. Payá, SF. Santos, MV Borrachero, J. Monzó, L. Soriano Use of highly reactive rice husk ash in the production of cement matrix reinforced with green coconut fiber. Industrial Crops and Products (2013) 49: 88-96. https://doi.org/10.1016/j.indcrop.2013.04.038

[13] VC. Correia; SF. Santos, GHD. Tonoli, H. Savastano Jr., Characterization of vegetable fibers and their application in cementitious composites. In: KA. Harries, B. Sharma (Eds.). Nonconventional and Vernacular Construction Materials: Characterization, Properties and Applications. Woodhead Publishing, Duxford, 2016, 83-110. https://doi.org/10.1016/B978-0-08-100038-0.00004-4

[14] Bentur, S. Mindess, Fibre Reinforced Cementitious Composites, 2nd edition; Taylor \& Francis, New York, 2007, 449.

[15] SF. Santos, GHD. Tonoli, JEB. Mejia, J. Fiorelli, H. Savastano Jr., Nonconventional cement-based composites reinforced with vegetable fibers: A review of strategies to improve durability. Materiales de Construcción (2015) 65 (317): 1-20.

[16] ETERNIT. Corporate Profile (Report). Eternit, São Paulo, 2015 (in Portuguese).

[17] V. Agopyan, H. Savastano Jr., V.M. John, MA. Cincotto, Developments on vegetable fibre-cement based materials in São Paulo, Brazil: an overview. Cem Concr Compos (2005) 27: 527-536. https://doi.org/10.1016/j.cemconcomp.2004.09.004

[18] F. Pacheco-Torgal, S. Jalali, Cementitious building materials reinforced with vegetable fibres: A review. Constr Build Mater (2011) 25: 575-581. https://doi.org/10.1016/j.conbuildmat.2010.07.024

[19] M. Ardanuy, J. Claramunt, RD. Toledo Filho, Cellulosic fiber reinforced cement-based composites: A review of recent research. Constr Build Mater (2015) 79: 115-128. https://doi.org/10.1016/i.conbuildmat.2015.01.035

[20] LTT. Vo, P. Navard, Treatments of plant biomass for cementitious building materials - A review. Constr Build Mater (2016) 121: 161176. https://doi.org/10.1016/j.conbuildmat.2016.05.125

[21] VC. Correia, V. Santos, M. Sain, SF. Santos, AL. Leão, H. Savastano Jr., Grinding process for the production of nanofibrillated cellulose based on unbleached and bleached bamboo organosolv pulp. Cellulose (2016) 23: 2971-2987. https://doi.org/10.1007/s10570-016-0996-9

[22] VC. Correia, SF. Santos, G. Mármol, AAS. Curvelo, H. Savastano Jr., Potential of bamboo organosolv pulp as reinforcement element in fiber-cement. Constr Build Mater (2014) 72: 65-71. https://doi.org/10.1016/i.conbuildmat.2014.09.005

[23] H. Savastano Jr., PG. Warden, RSP. Coutts, Microstructure and mechanical properties of waste fibre-cement composites, Cem Concr Compos (2005) 27: 583 - 592. https://doi.org/10.1016/i.cemconcomp.2004.09.009 
[24] FA. Silva, N. Chawla, R. D. Toledo Filho, An experimental investigation of the fatigue behavior of sisal fibers. Mat Sci Eng AStruc (2009) 516: 90-95 https://doi.org/10.1016/j.msea.2009.03.026

[25] J. Wei, C. Meyer, Utilization of rice husk ash in green natural fiberreinforced cement composites: Mitigating degradation of sisal fiber. Cement Concrete Res (2016) 81: 94-111. https://doi.org/10.1016/j.cemconres.2015.12.001

[26] SR. Ferreira, FA. Silva, PRL. Lima, RD. Toledo Filho, Effect of hornification on the structure, tensile behavior and fibre matrix bond of sisal, jute and curauá fiber cement based composite systems. Constr Build Mater (2017) 139: 551-561. https://doi.org/10.1016/i.conbuildmat.2016.10.004

[27] R. Jarabo, MC. Monte, A. Blanco, C. Negro, J. Tijero, Characterisation of agricultural residues used as a source of fibres for fibre-cement production. Ind Crop Prod (2012) 36: 14-21. https://doi.org/10.1016/i.indcrop.2011.07.029

[28] CL. Pereira, H. Savastano Jr., J. Payá, SF. Santos, MV. Borrachero, J. Monzó, L. Soriano, Use of highly reactive rice husk ash in the production of cement matrix reinforced with green coconut fiber. Ind Crop Prod (2013) 49: 88-96. https://doi.org/10.1016/j.indcrop.2013.04.038

[29] EJ. Silva, ML. Marques, FG. Velasco, C. Fornari Junior, FM. Luzardo, MM. Tashima, A new treatment for coconut fibres to improve the properties of cement-based composites - Combined effect of natural latex/pozzolanic materials. Sustainable Materials and Technologies (2017) 12: 44-51. https://doi.org/10.1016/j.susmat.2017.04.003

[30] M. Khorami, E. Ganjian, Comparing flexural behaviour of fibrecement composites reinforced bagasse: Wheat and eucalyptus. Constr Build Mater (2011) 25: 3661-3667. https://doi.org/10.1016/j.conbuildmat.2011.03.052

[31] A. D'Almeida, R. Toledo Filho, J. Melo Filho, Cement composites reinforced by short curauá fibers. Matéria (2010) 15 (2): 151-156. https://doi.org/10.1590/S1517-70762010000200010

[32] DG. Soltan, P. Neves, A. Olvera, H. Savastano Jr., VC. Li, Introducing a curauá fiber reinforced cement-based composite with strainhardening behavior. Ind Crop Prod (2017)103: 1-12. https://doi.org/10.1016/j.indcrop.2017.03.016

[33] X. Xie, Z. Zhou, M. Jiang, X. Xu, Z. Wang, D. Hui, Cellulosic fibres from rice straw and bamboo used as reinforcement of cement-based composites for remarkably improving mechanical properties. Compos Part B-Eng (2015) 78: 153-161. https://doi.org/10.1016/i.compositesb.2015.03.086

[34] Campello, E. F.; Pereira, M. V.; Darwish, F. A.; Ghavami, K. On the Fatigue Behavior of Bamboo Pulp Reinforced Cementitious Composites. Procedia Struct Integrity (2016) 2: 2929-2935. https://doi.org/10.1016/i.prostr.2016.06.366

[35] GHD. Tonoli, UP. Rodrigues Filho, H. Savastano Jr, J. Bras, MN. Belgacem, FAR. Lahr, Cellulose modified fibres in cement based composites. Compos Part A-Appl S (2009) 40: 2046-2053. https://doi.org/10.1016/i.compositesa.2009.09.016

[36] GE. Urrea-Ceferino, N. Rempe, V. Santos, H. Savastano Jr., Definition of optimal parameters for supercritical carbonation treatment of vegetable fiber-cement composites at a very early age. Constr Build Mater (2017) 152: 424-433. https://doi.org/10.1016/j.conbuildmat.2017.06.182

[37] G. Mármol, H. Savastano Jr., Study of the degradation of nonconventional $\mathrm{MgO}-\mathrm{SiO} 2$ cement reinforced with lignocellulosic fibers. Cem Concr Compos (2017) 80: 258-267. https://doi.org/10.1016/j.cemconcomp.2017.03.015

[38] GHD. Tonoli, SF. Santos, H. Savastano Jr., S. Delvasto, R. Mejía de Gutiérrez, M. Lopez de Murphy, Effects of natural weathering on microstructure and mineral composition of cementitious roofing tiles reinforced with fique fibre. Cem Concr Compos (2011) 33: 225232. https://doi.org/10.1016/j.cemconcomp.2010.10.013

[39] RSP. Coutts, PG. Warden, Sisal pulp reinforced cement mortar. Cem Concr Compos (1992) 14: 17-21. https://doi.org/10.1016/0958-9465(92)90035-T

[40] JA. Melo Filho, FA. Silva, RD. Toledo Filho, Degradation kinetics and aging mechanisms on sisal fiber cement composite systems. Cem Concr Compos (2013) 40: 30-39. https://doi.org/10.1016/i.cemconcomp.2013.04.003

[41] B. Shen, M. Hubler, GH. Paulino, U. Struble, Functionally-graded fiber-reinforced cement composite: Processing, microstructure, and properties. Cem Concr Compos (2008) 30 (8): 663-673. https://doi.org/10.1016/i.cemconcomp.2008.02.002
[42] CMR. Dias, H. Savastano Jr., VM. John, Exploring the potential of functionally graded materials concept for the development of fiber cement. Constr Build Mater (2010) 24 (2): 140-146. https://doi.org/10.1016/j.conbuildmat.2008.01.017

[43] JL. Provis, Geopolymers and other alkali activated materials: why, how, and what? Mater Struct (2014) 47: 11-25. https://doi.org/10.1617/s11527-013-0211-5

[44] G. Mármol, H. Savastano Jr, MM. Tashima, JL. Provis, Optimization of the $\mathrm{MgO}$ single bond $\mathrm{SiO} 2$ binding system for fiber-cement production with cellulosic reinforcing elements. Mater Design (2016) 105: 251-261. https://doi.org/10.1016/i.matdes.2016.05.064

[45] B. Šavija, M. Luković, Carbonation of cement paste: Understanding, challenges, and opportunities. Constr Build Mater (2016) 117: 285301. https://doi.org/10.1016/j.conbuildmat.2016.04.138

[46] AEFS. Almeida, GHD. Tonoli, SF. Santos, H. Savastano Jr., Improved durability of vegetable fiber reinforced cement composite subject to accelerated carbonation at early age. Cem Concr Compos (2013) 42: 49-58. https://doi.org/10.1016/j.cemconcomp.2013.05.001

[47] VC. Li, Integrated structures and materials design. Mater Struct (2007) 40 (4): 387-396. https://doi.org/10.1617/s11527-006-9146-4

[48] O. Faruk, AK. Bledzki, HP. Fink, M. Sain, Biocomposites reinforced with natural fibers: 2000-2010. Prog Polym Sci (2012) 37 (11): 1552 1596. https://doi.org/10.1016/i.progpolymsci.2012.04.003

[49] SR. Karade, Cement-bonded composites from lignocellulosic wastes. Constr Build Mater (2010) 24 (8): 1323-1330. https://doi.org/10.1016/j.conbuildmat.2010.02.003

[50] MJ. Le Guen, RH. Newman, Pulped Phormium tenax leaf fibres as reinforcement for epoxy composites. Compos Part A-Appl S (2007) 38 (10): 2109-2115. https://doi.org/10.1016/j.compositesa.2007.07.001

[51] GHD. Tonoli, H. Savastano Jr., E. Fuente, C. Negro, A. Blanco, FA. Rocco Lahr, Eucalyptus pulp fibres as alternative reinforcement to engineered cement-based composites. Ind Crop Prod (2010) 31: 225-232. https://doi.org/10.1016/j.indcrop.2009.10.009

[52] LC. Roma, LS. Martello, H. Savastano Jr., Evaluation of mechanical, physical and thermal performance of cement-based tiles reinforced with vegetable fibers. Constr Build Mater (2008) 22: 668 - 674. https://doi.org/10.1016/j.conbuildmat.2006.10.001

[53] H. Savastano Jr., PG. Warden, RSP. Coutts, Brazilian Waste Fibres As Reinforcement For Cement Based Composites. Cem Concr Compos (2000) 22 (5): 379-384. https://doi.org/10.1016/S0958-9465(00)00034-2

[54] H. Savastano Jr., PG. Warden, RSP. Coutts, Mechanically pulped sisal as reinforcement in cementitious matrices. Cem Concr Compos (2003) 25: 311-319. https://doi.org/10.1016/S0958-9465(02)00055-0

[55] H. Savastano Jr., SF. Santos, M. Radonjic, WO. Soboyejo, Fracture and fatigue of natural fiber-reinforced cementitious composites. Cem Concr Compos (2009) 31: 232 - 243. https://doi.org/10.1016/i.cemconcomp.2009.02.006

[56] RD. Toledo Filho, K. Scrinever, GL. England, K. Ghavami, Durability of alkalisensitive sisal and coconut fibres in cement mortar composites. Cem Concr Compos (2000) 22: 127-143. https://doi.org/10.1016/S0958-9465(99)00039-6

[57] J. Claramunt, M. Ardanuy, JA. García-Hortal, RD. Toledo Filho, The hornification of vegetable fibers to improve the durability of cement mortar composites. Cem Concr Compos (2011) 33: 586-595. https://doi.org/10.1016/j.cemconcomp.2011.03.003

[58] M. Khorami, E. Ganjian, The effect of limestone powder, silica fume and fibre content on flexural behaviour of cement composite reinforced by waste Kraft pulp. Constr Build Mater (2013) 46: 142149. https://doi.org/10.1016/j.conbuildmat.2013.03.099

[59] HPS. Abdul Khalil, Y. Davoudpour, Md. Nazrul Islam, A. Mustapha, K. Sudesh, R. Dungani, M. Jawaid, Production and modification of nanofibrillated cellulose using various mechanical processes: A review. Carbohyd Polym (2014) 99: 649-665. https://doi.org/10.1016/j.carbpol.2013.08.069

[60] L. Brinchi, F. Cotana, E. Fortunati, JM. Kenny, Production of nanocrystalline cellulose from lignocellulosic biomass: Technology and applications. Carbohyd Polym (2013) 94: 154-169. https://doi.org/10.1016/i.carbpol.2013.01.033

[61] A.Chakraborty, M. Sain, M. Kortschot, Reinforcing potential of wood pulp derived microfibres in a PVA matrix. Holzforschung (2006) 60: 53-58. https://doi.org/10.1515/HF.2006.010

[62] K. Missoum, MN. Belgacem, J. Bras, Nanofibrillated Cellulose Surface Modification: A Review. Materials (2013) 6: 1745-1766. https://doi.org/10.3390/ma6051745 
[63] MJ. Hanus, AT. Harris, Nanotechnology innovations for the construction industry. Prog Mater Sci (2013) 58: 1056-1102. https://doi.org/10.1016/j.pmatsci.2013.04.001

[64] R. Siddique, A. Metha, Effect of carbon nanotubes on properties of cement mortars. Constr Build Mater (2014) 50: 116-129. https://doi.org/10.1016/j.conbuildmat.2013.09.019

[65] S. Alrekabi, AB. Cundy, A. Lampropoulos, RLD. Whitby, I. Savina, Mechanical performance of novel cement-based composites prepared with nano-fibres, and hybrid nano- and micro- fibres. Compos Struct (2017) 178: 145-156. https://doi.org/10.1016/i.compstruct.2017.06.045

[66] B. Han, X. Yu, J. Ou, Multifunctional and Smart Carbon Nanotube Reinforced Cement-Based Materials, in Nanotechnology in Civil Infrastructure, K. Gopalakrishnan, Ed. 2011, Springer Berlin Heidelberg. 1-47. https://doi.org/10.1007/978-3-642-16657-0 1

[67] P. Stynoski, P. Mondal, C. Marsh, Effects of silica additives on fracture properties of carbon nanotube and carbon fiber reinforced Portland cement mortar. Cem Concr Compos (2015) 55: 232-240. https://doi.org/10.1016/j.cemconcomp.2014.08.005

[68] GY. Li, PM. Wang, X. Zhao, Pressure-sensitive properties and microstructure of carbon nanotube reinforced cement composites. Cem Concr Compos (2007) 29: 377-382.

https://doi.org/10.1016/j.cemconcomp.2006.12.011

[69] L. Raki, J. Beaudoin, R. Alizadeh, J. Makar, T. Sato, Cement and Concrete Nanoscience and Nanotechnology. Materials (2010) 3 (2): 918-942. https://doi.org/10.3390/ma3020918

[70] B. Han, Z. Yang, X. Shi, X. Yu, Transport Properties of CarbonNanotube/Cement Composites. J Mater Eng Perform (2013) 22: 184-189. https://doi.org/10.1007/s11665-012-0228-x

[71] X. Sun, Q. Wu, S. Lee, Y. Qing, Y. Wu, Cellulose Nanofibres as a Modifier for Rheology, Curing and Mechanical Performance of Oil Well Cement. Sci Rep (2016) 6: 31654. https://doi.org/10.1038/srep31654

[72] ML. Hassan, AP. Mathew, EA. Hassan, N. El-Wakil, K. Oksman, Nanofibers from bagasse and rice straw: process optimization and properties. Wood Sci Technol (2012) 46: 193-205. https://doi.org/10.1007/s00226-010-0373-z

[73] Y. Cao, N. Tian, D. Bahr, PD. Zavattieri, J. Youngblood, RJ. Moon, J. Weiss, The influence of cellulose nanocrystals on the microstructure of cement paste. Cem Concr Compos (2016) 74: 164-173. https://doi.org/10.1016/i.cemconcomp.2016.09.008

[74] Y. Cao, P. Zavattieri, J. Youngblood, R. Moon, J. Weiss, The relationship between cellulose nanocrystal dispersion and strength. Constr Build Mater (2016) 119: 71-79. https://doi.org/10.1016/i.conbuildmat.2016.03.077

[75] Y. Cao, P. Zavaterri, J. Youngblood, R. Moon, J. Weiss, The influence of cellulose nanocrystal additions on the performance of cement paste. Cem Concr Compos (2015) 56: 73-83. https://doi.org/10.1016/i.cemconcomp.2014.11.008

[76] J. Flores, M. Kamali, A. Ghahremaninezhad, An Investigation into the Properties and Microstructure of Cement Mixtures Modified with Cellulose Nanocrystal. Materials (2017) 10 (5): 1-16.

[77] SL. Thomson, DJ. O'Callaghan, JA. Westland, B. Su, Method of making a fiber cement board with improved properties of the product. Patent US 2010/0162926 AL, 2010.

[78] M. Ardanuy, J. Claramunt, R. Arévalo, F. Parés, Nanofibrillated cellulose (NFC) as a potential reinforcement for high performance cement mortar composites. BioResources (2012) 73 (3): 3883-3894.

[79] M. Ardanuy, J. Claramunt, RD. Toledo Filho, Evaluation of durability tp wet/dry cycling of cement mortar composites reinforced with nanofibrillated cellulose. Brittle Matrix Composites (2012) 10: 33-41, 2012.

[80] O. Onuaguluchi, DK. Panesar, M. Sain, Properties of nanofibre reinforced cement composites. Constr Build Mater (2014) 63: 119124. https://doi.org/10.1016/j.conbuildmat.2014.04.072

[81] SF. Santos, R. Schmidt, AEFS. Almeida, GHD. Tonoli, H. Savastano Jr., Supercritical carbonation treatment on extruded fibre-cement reinforced with vegetable fibres. Cem Concr Compos (2015) 56: 8494. https://doi.org/10.1016/j.cemconcomp.2014.11.007

[82] VC. Correia, SF. Santos, RS. Teixeira, H. Savastano Jr., Nanofibrillated cellulose and cellulosic pulp for reinforcement of the extruded cement based materials. Construction and Building Materials (2018) 160: 376-384. https://doi.org/10.1016/j.conbuildmat.2017.11.066 